\title{
EFFeCT OF PARTICleboard COATING ON FLEXUAL STRENGTH AND MODULUS OF ELASTICITY
}

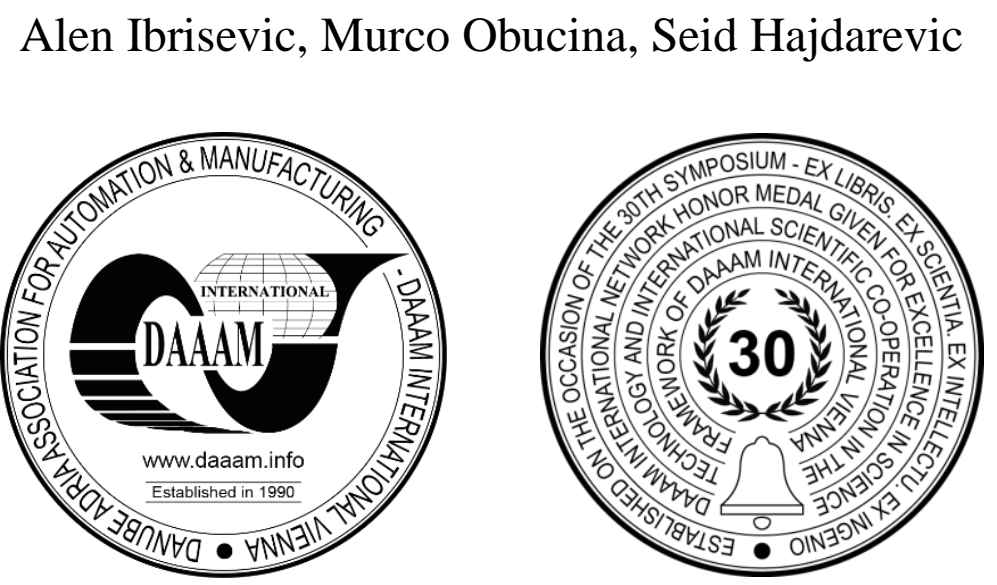

This Publication has to be referred as: Ibrisevic, A[len]; Obucina, M[urco] \& Hajdarevic, S[eid] (2019). Effect of Particleboard Coating on Flexual Strength and Modulus of Elasticity, Proceedings of the 30th DAAAM International Symposium, pp.0892-0896, B. Katalinic (Ed.), Published by DAAAM International, ISBN 978-3-902734-22-8, ISSN 1726-9679, Vienna, Austria

DOI: $10.2507 / 30$ th.daaam.proceedings.124

\begin{abstract}
This paper analyses changes in the flexural strength and the modulus of elasticity on particleboard depending on the material used for particleboard coating. Three-layer $18 \mathrm{~mm}$ thick particleboard which is mainly used in the manufacture of furniture was coated with several different coating materials. The coating was done with beech veneer (1-3 layers), melamine foil and ultrapas. A number of tubes were also varnished (PU varnish) after they were coated with a single layer of veneer, after which the effect of varnishing on the flexural strength and the modulus of elasticity was analysed. It was concluded that coating and the properties of the coating material affect the flexural strength and the modulus of elasticity.
\end{abstract}

Keywords: flexural strength; modulus of elasticity; particleboard; coating

\section{Introduction}

Panels made of wood chips are nowadays widely used in numerous people's activities, particularly in furniture industry and civil engineering. The most frequently used panels made of wood chips are particleboards. Particleboard represent a class of wood-based composite with fine wood fibers bound together by a small amount of polymeric adhesive [1].

Particleboard is a material produced in large quantities, and it is mainly used in the manufacture of furniture, where good mechanical properties are combined with good processability of such boards [2]. Particleboard is a dominant wood-based panel material in the territory of Bosnia and Herzegovina. Particleboard is the most frequently used panel material worldwide for non-structural use. The high popularity of particle board comes from a lower price in comparison with the other types of wood-based panel materials, and from its flexibility [3].

Particleboard is a semi-finished product (raw board) with a wide range of possibilities for use. It is usual nowadays for particleboards intended for furniture industry and interior design to be coated in a certain manner before they are installed in the final product.

Particleboard coating means coating the board surface with materials which have a more decorative look and higher resistance to the effects of external causes in comparison with the board itself [4]. Coating with different coating materials 
results in changing the basic mechanical properties (modulus of elasticity E and flexural strength) of particleboards [5]. Apart from improving the basic mechanical properties, particleboard coating also results in improving the surface quality and the aesthetic properties of the board, increasing the age resistance and decreasing the formaldehyde emission, i.e. it contributes to obtaining a better quality and more expensive product. For outside use of particleboard the surface of boards is coated by different processes. Nowadays, particleboard panel products are coated by impregnated papers, paint, print, varnish, veneers, laminates, foils, etc [6]. In furniture industry, particleboards are mainly coated with veneers and with PVC foils.

Particleboards are nowadays mainly used in the manufacture of furniture (corporate furniture), wall cladding, flooring, etc. In corporate structures, boards are acted on by various forces causing deformation of the board and of the entire corporate structure. The load results in the occurrence of stress in the corporate structures. The most frequent type of stress in corporate structures is bending stress. If the stress exceeds the elastic limit, boards are permanently bended, or, in extreme cases, broken. Fracture strength means the maximum shear strength in the grain direction [7].In the event of temporal load, particle boards will creep. This phenomenon is particularly pronounced with corporal structure shelves.

The objective of research for this paper is to find solutions in order to reduce bending deformations of particle boards and to increase their modulus of elasticity. The only solution leading to the increase in the flexural strength and the bending modulus of elasticity is particle board coating.

\section{Experimental part}

The testing of the flexural strength and the bending modulus of elasticity conducted for this paper was done in accordance with the BAS EN 310:2001 standard. For the purpose of the experiment, the particleboard was coated, after which a number of tubes were cut out of such boards to determine the flexural strength and the bending modulus of elasticity. The particleboard coating and the cutting out of the tubes were done at the furniture factory "Jadrina" in Gracanica. For the purpose of the experiment, the particleboards were coated with different coating materials. The material used for the experiment was three-layer $18 \mathrm{~mm}$ thick particleboard, produced at the particle board factory "Iverica" in Bjelovar.

The material used for overlaying was $0.6 \mathrm{~mm}$ thick beech veneer. The veneer moisture level before the compression was $3.1 \%$, and the particleboard moisture level before the compression was $6.9 \%$. The veneer was glued to the raw particleboard using urea-formaldehyde adhesive. The compression was done in the single-opening press produced by "ITALPRESSE", Brescia, Italy. The compression temperature was $\mathrm{T}=95{ }^{\circ} \mathrm{C}$, and the pressure was $0.5 \mathrm{MPa}$. When overlaying the board with two and three layers of veneer, the veneers in different layers were mutually perpendicular (like with veneer boards), i.e. the structure symmetry rule was obeyed. After the boards were overlaid with veneer, they were conditioned at the temperature of $\mathrm{t}=25^{\circ} \mathrm{C}$ and the relative humidity of $36 \%$. The boards were conditioned for 48 hours. The tubes were varnished with two layers of polyurethane varnish. The varnishing was done using Heliodur polyurethane varnish, produced by Helios, Domzale, Slovenia. The tubes coated with decorative foil were tested using particle board coated at the particle board factory "Iverica" in Bjelovar. The particleboard was coated with foil weighing $70-100 \mathrm{~g} / \mathrm{m}^{2}+$ $4 \mathrm{~g} / \mathrm{m}^{2}$. At the end, the particle board was coated with ultrapas. The coating with ultrapas was done in the same manner as the coating with veneers, i.e. using the same equipment and the same adhesive. The data on the composition and the properties of the ultrapas used are not known.

According to the BAS EN 310:2001, the flexural strength is calculated using the following formula:

$$
\sigma_{\mathrm{s}}=\frac{3 \cdot F_{\max } \cdot l_{1}}{2 \cdot b \cdot d^{2}}
$$

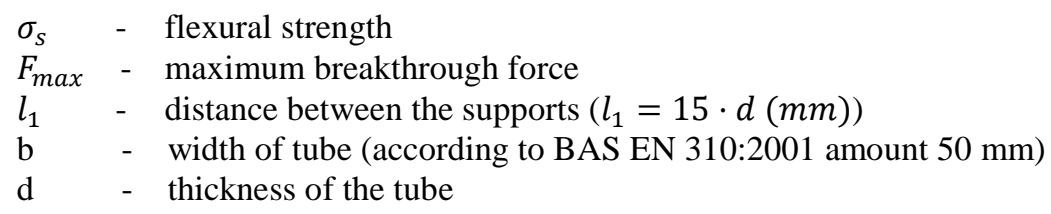

The flexural strength of the coated particleboards was tested using the destructive method on a "ZWICK" testing machine. The testing was done in such a manner that the press on the testing machine moved and thereby exerted pressure on the tube, due to which the tube eventually broke. The breaking force is read on a digital display. The tube breaks when the force exceeds the allowable bending stress. The breaking force and the other predefined parameters (width and thickness of the tube, and the distance between the supports) are included in the formula (1), and the flexural strength is calculated in that way. 

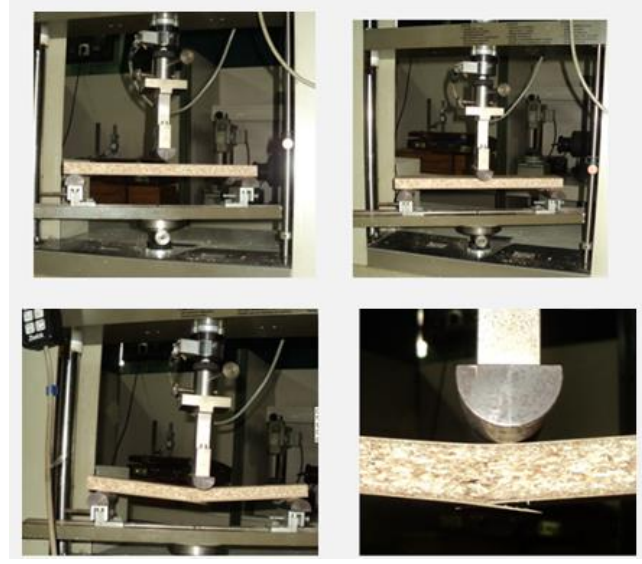

Fig. 1. Flexural strength test procedure

The bending modulus of elasticity was tested using the non-destructive method of determination of the modulus of elasticity. The tubes were loaded with the $10 \%$ value of the mean value of the breaking force $\left(F_{10 \%}\right)$, and the deflection value in mm was read on the digital display. The read value represents a variable. After that, the tubes were loaded with the $40 \%$ value of the mean value of the breaking force $\left(F_{40 \%}\right)$, and the deflection value was read. The read deflection value represents a variable $a_{1}$.

The obtained variables were included in the formula for calculating the modulus of elasticity (2).

According to the BAS EN 310:2001, the modulus of elasticity of particl boards is calculated using the following formula:

$$
\mathrm{E}_{\mathrm{s}}=\frac{l_{1}{ }^{3} \cdot\left(\mathrm{F}_{2}-\mathrm{F}_{1}\right)}{4 \cdot \mathrm{b} \cdot \mathrm{d}^{3} \cdot\left(\mathrm{a}_{2}-\mathrm{a}_{1}\right)}
$$

$E_{S} \quad-\quad$ modulus of elasticity

$l_{1} \quad-$ distance between the supports

$F_{2} \quad-\quad F_{F 40 \% \text { max }}(40 \%$-value of the mean fracture force)

$F_{1} \quad-F_{F 10 \% \text { Fmax }}(10 \%$-value of the mean fracture force)

b - width of tube (according to BAS EN 310:2001 amount $50 \mathrm{~mm}$ )

d - thickness of the tube

$a_{2} \quad$ - deflection value at $40 \%$-value of the mean fracture force

$a_{1} \quad$ - deflection value at $10 \%$-value of the mean fracture force

\section{Results and discussion}

The flexural strength for particleboards coated with different coating materials is shown in Image 2.

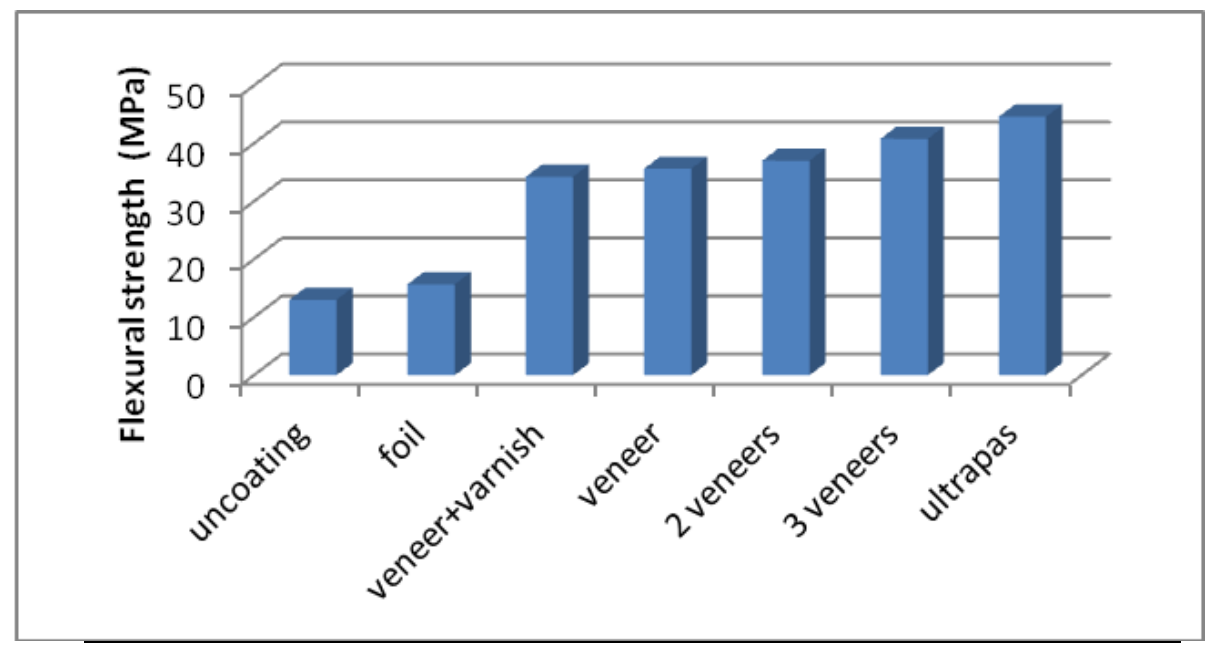

Fig. 2. Flexural strength for particleboards coated with different materials 
Image 2. shows that the flexural strength of non-coated particleboard totals $\sigma_{s}=13.02 \mathrm{MPa}$. After the coating with different materials, the flexural strength changes to a lesser or to a greater extent.

Image 2. also shows that the highest value of the flexural strength is obtained if particle board is coated with ultrapas, while the flexural strength has the lowest value if particle board is coated with decorative foil. Surface treatment does not result in an increase in the flexural strength. The comparative results of the flexural strength test for particle boards coated with different materials are shown in Table 1.

\begin{tabular}{|c|c|c|c|c|c|c|c|}
\cline { 2 - 8 } \multicolumn{1}{c|}{} & uncoating & foil & 1 veneer+varnish & 1 venner & 2 venner & 3 veneer & ultrapas \\
\hline uncoating & 0 & $21 \%$ & $163 \%$ & $174 \%$ & $184 \%$ & $213 \%$ & $243 \%$ \\
\hline foil & & 0 & $118 \%$ & $126 \%$ & $136 \%$ & $160 \%$ & $184 \%$ \\
\hline 1 veneer+varnish & & & 0 & $4 \%$ & $8 \%$ & $19 \%$ & $30 \%$ \\
\hline 1 veneer & & & & 0 & $4 \%$ & $15 \%$ & $25 \%$ \\
\hline 2 veneer & & & & & 0 & $10 \%$ & $20 \%$ \\
\hline 3 veneer & & & & & & 0 & $9 \%$ \\
\hline ultrapas & & & & & & & 0 \\
\hline
\end{tabular}

Table 1. Increase in the flexural strength (in percentage points) for particleboard coated with different materials

The bending modulus of elasticity is shown in Image 3.

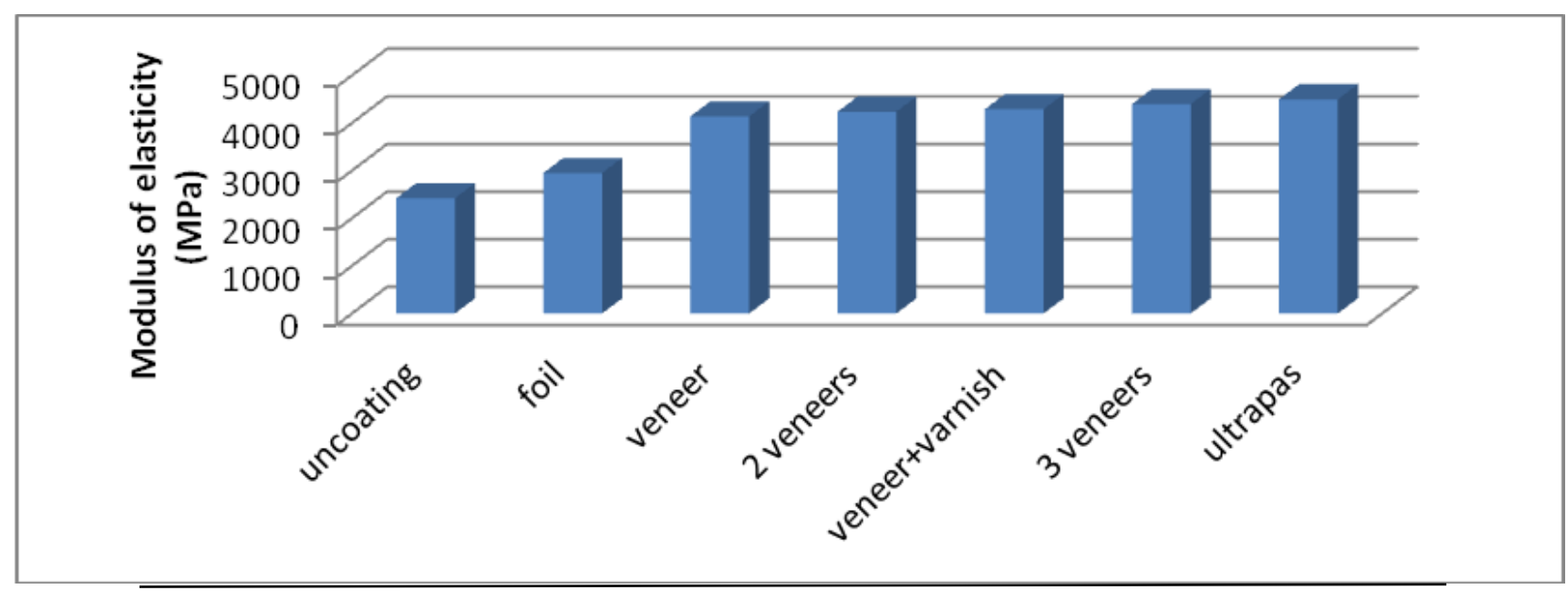

Fig. 3. Bending modulus of elasticity for particleboard coated with different materials

Image 3. shows that the type of material used for coating has a crucial effect on the mechanical properties of the board, i.e. on the bending modulus of elasticity. The image shows that an increase in the number of layers results in an increase in the modulus of elasticity. The comparative results of the modulus of elasticity test for particle boards coated with different materials are shown in Table 2.

\begin{tabular}{|c|c|c|c|c|c|c|c|}
\hline & uncoating & foil & veneer & 2 veneer & veneer+varnish & 3 veneer & ultrapas \\
\hline uncoating & 0 & $21 \%$ & $71 \%$ & $75 \%$ & $77 \%$ & $82 \%$ & $86 \%$ \\
\hline foil & & 0 & $40 \%$ & $43 \%$ & $45 \%$ & $49 \%$ & $52 \%$ \\
\hline veneer & & & 0 & $2 \%$ & $4 \%$ & $6 \%$ & $9 \%$ \\
\hline 2 veneers & & & & 0 & $1 \%$ & $4 \%$ & $6 \%$ \\
\hline veneer+varnish & & & & & 0 & $3 \%$ & $5 \%$ \\
\hline 3 veneer & & & & & & 0 & $2 \%$ \\
\hline ultrapas & & & & & & & $2 \%$ \\
\hline
\end{tabular}

Table 2. Increase in the bending modulus of elasticity for particle board coated with different materials

The table shows that the lowest value of the modulus of elasticity is obtained if particleboard is coated with decorative foil, while the modulus of elasticity has the highest value if particleboard is coated with ultrapas. Surface treatment does not result in an increase in the modulus of elasticity. 


\section{Conclusion}

This study confirmed that particleboard coating results in an increase in the flexural strength and the bending modulus of elasticity. The lowest increase in these parameters was recorded when particleboard was coated with decorative foil $\left(\sigma_{s}=15.70 \mathrm{MPa}, E_{s}=2948.8 \mathrm{MPa}\right)$, while the highest values of these parameters were obtained when particle board was coated with ultrapases $\left(\sigma_{s}=44.62 \mathrm{MPa}, E_{s}=4496.05 \mathrm{MPa}\right)$. When particleboard is coated with ultrapases, the flexural strength increases by $243 \%$, while the modulus of elasticity increases by $86 \%$ in comparison with non-coated board. An increase in the number of veneer layers results in an increase in the values of the flexural strength and the bending modulus of elasticity, and the increase is linear. During the surface treatment, the flexural strength and the bending modulus of elasticity change (it was established in the experiment), but the t-test and the f-test showed that tubes coated with veneer and varnish belong to the same set as tubes coated with veneer, and any change in the mechanical properties is therefore merely accidental.

In future research should be continued testing the flexural strength and the bending modulus of elasticity of particleboard coating with new material (tire, plastic, linoleum, metal) and also testing the flexural strength and the bending modulus of elasticity with combination of different material for caoating.

\section{References}

[1] Marsavina L., Octavian Pop I., Linul E., (2019): Mechanical and fracture properties of particleboard. Frattura ed Integrità Strutturale, 47 (2019) 266-276; DOI: 10.3221/IGF-ESIS.47.20

[2] Cai Z. (2004): Evaluating the warping of laminated particleboard panels. The 7th Pacific Rim Bio-Based Composites Symposium, Nanjing.

[3] Wong, D.C., Kozak, R.A. (2008): Particleboard performance requirements of secondary wood products manufacturers in Canada. Forest Products Journal. 58(3): 34-41.

[4] Karahasanović A., Rajman V., (1970): Lesonit i iverice; Dio 2 iverice. Univerzitet u Sarajevu, Sarajevo.

[5] Norvydas V., Minelga D., (2006): Strength and Stiffness Properties of Furniture Panels Covered with Different Coatings. Materials Sciences. 12 (4): 328-332.

[6] Istek A., Aydemir D., Aksu S. (2010): The effect of décor paper and resin type on the physical, mechanical, and surface quality properties of particleboards coated with impregnated décor papers. Bioresources 5(2):1074-1083

[7] Obucina M., Gondzic E., Manso E. (2014): The Influenceof AdhesionTemperature to the Shear Strength of Width Glued Wooden Elements. 25th DAAAM International Symposium on Intelligent Manufacturing and Automation, DAAAM 2014

[8] Seferović E., Bašić H. (2005): Osnovi metrologije i obrade podataka. Mašinski fakultet, Sarajevo.

[9] BAS EN 310:2001 